Casos Clínicos

Arch. Esp. Urol., 61, 5 (631-633), 2008

\section{RIÑÓN ECTÓPICO INTRATORÁCICO EN UN ADULTO: APORTACIÓN DE UN CASO Y REVISIÓN DE LA LITERATURA}

Fernando Vázquez Alonso, Francisco Javier Vicente Prados, Manrique Pascual Geler, Carlos Funes Padilla, Manuel Segura Sánchez, Antonio Fernández Sánchez, Francisco Rodríguez Herrera, Antonio Martínez Morcillo, José Manuel Cózar Olmo, Eduardo Espejo Maldonado y Miguel Tallada Buñuel.

Hospital Universitario Virgen de las Nieves de Granada. Granada. España.

Resumen.- OBJETIVO: Se presenta el caso clínico de un varón de 61 años diagnosticado de manera incidental de ectopia renal intratorácica durante el estudio de posible masa pulmonar.

MÉTODOS: Se realiza una revisión bibliográfica de la incidencia, origen, clínica y diagnóstico de este tipo de ectopia renal.

RESULTADOS: En la radiografía de tórax se aprecia una masa en mediastino posterior izquierdo. Es practicada una

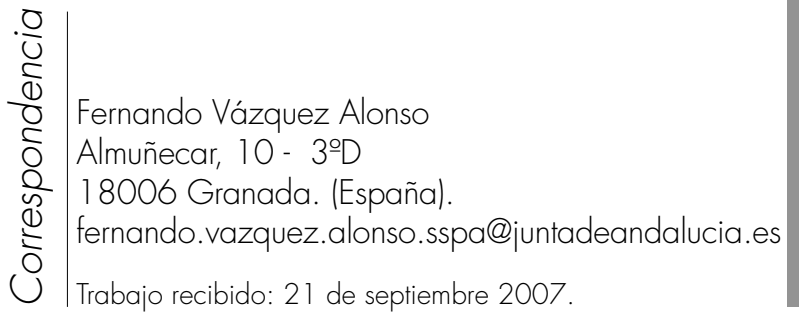

fibrobroncoscopia apreciando signos de compresión extrínseca con ausencia de células neoplásicas. El TAC revela un riñón ectópico intratorácico con hernia diafragmática izquierda.

CONCLUSIONES: La ectopia renal intratorácica es un hallazgo muy infrecuente, habitualmente asintomático, diagnosticado con frecuencia de manera incidental y que no suele requerir tratamiento.

Palabras clave: Riñón intratorácico. Hernia diafragmática. Diagnóstico.

Summary.- OBJECTIVE: We report the case of a 67year-old male with the incidental diagnosis of intrathoracic renal ectopia during the workup study for a possible lung mass.

METHODS: We performed a bibliographic review on the incidence, origin, clinical presentation and diagnosis of this type of renal ectopia.

RESULTS: Chest x-ray showed a left posterior mediastinum mass. Bronchoscopy was performed showing signs of extrinsic compression with absence of neoplastic cells. CT scan revealed a left intrathoracic ectopic kidney with diaphragmatic hernia.

CONCLUSIONS: Intrathoracic renal ectopia is a very unfrequent finding, often asymptomatic, frequently an incidental diagnosis that does not require treatment.

Keywords: Intrathoracic kidney. Diaphragmatic hernia. Diagnosis.

\section{INTRODUCCIÓN}

La localización anómala del riñón se denomina ectopia renal. La ectopia renal intratorácica es un hallazgo muy poco frecuente, con una incidencia inferior a 1 de cada 10.000 (1), que afecta preferentemente al riñón izquierdo puesto que el hígado protege al diafragma derecho contra los cambios de presión (2).

Aportamos un nuevo caso y realizamos una revisión de la literatura.

\section{CASO CLÍNICO}

Paciente de 61 años con antecedentes de ACV sin secuelas, estenosis mitral severa, fibrilación auricular crónica y EPOC moderado. 


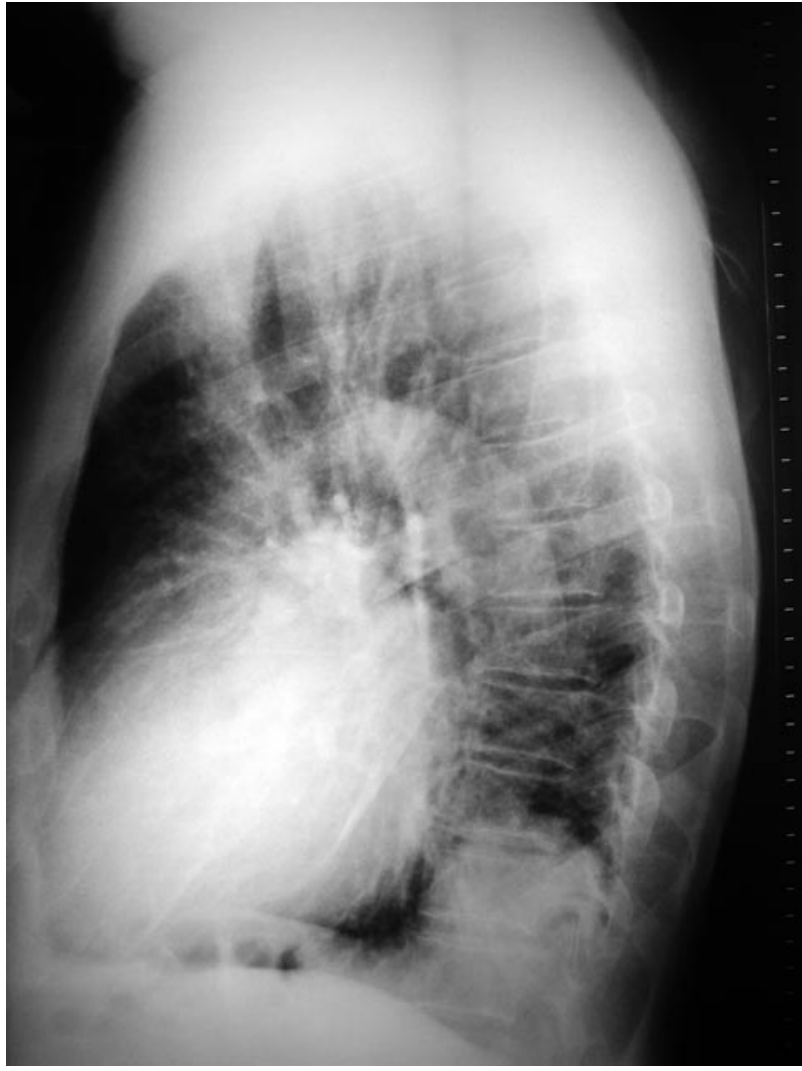

FIGURA 1. Radiografía de tórax: masa en mediastino posterior.

Es estudiado en consulta de Neumología por cuadro de aumento de disnea habitual, expectoración mucosa y ocasionalmente hemoptoica. El hemograma y la bioquímica fueron normales. En la radiografía de tórax (Figura 1) se aprecia condensación en base izquierda sin broncograma, sospechando una neoplasia pulmonar, por lo que se practica TAC torácico (Figura 2) que evidencia riñón izquierdo ectópico intratorácico con hernia hemidiafragmática izquierda, con buena excreción renal bilateral, originando una atelectasia segmentaria de segmentos basales mediales del lóbulo inferior izquierdo. En fibrobroncoscopia a nivel de base izquierda en segmento seis y segmentos posteriores de pirámide basal se aprecian signos de compresión extrínseca practicando a este nivel bronco-aspirado alveolar con ausencia de células neoplásicas.

El paciente negaba antecedentes de traumatismo torácico previo. Actualmente se encuentra estable desde el punto de vista respiratorio.

\section{DISCUSIÓN}

La ectopia renal intratorácica es una entidad muy poco frecuente que representa menos del $5 \%$ de las ectopias y es más frecuente en hombres que en mujeres (3).

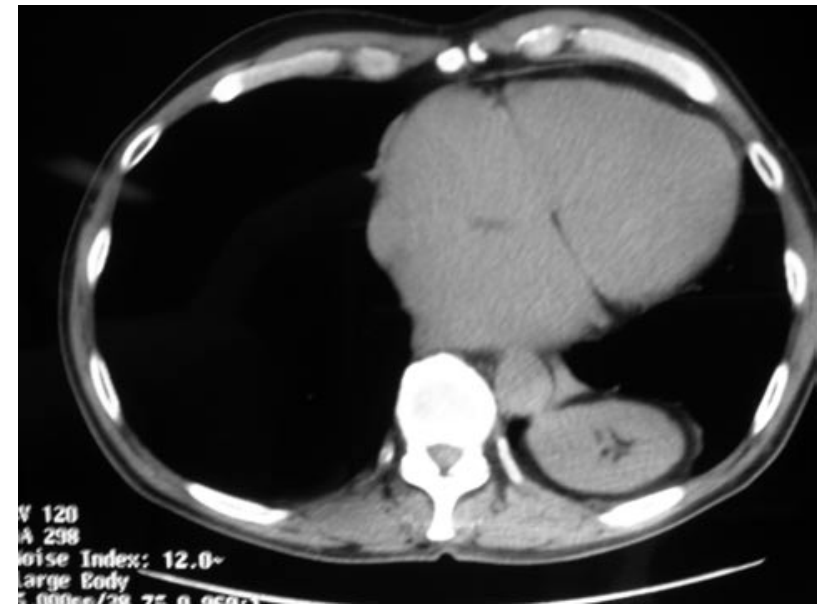

FIGURA 2. TAC torácico: riñón ectópico intratorácico izquierdo.

Puede tratarse de una ectopia renal verdadera intratorácica, presente en la vida fetal, en la que el pedículo vascular renal nace de la aorta descendente intratorácica, y por otra parte puede producirse una ascensión renal transdiafragmática al tórax en la que los vasos renales tienen su origen normal en la aorta abdominal (4). Este segundo caso puede tener dos orígenes, uno congénito que es el más frecuente y que suele ser consecuencia de una hernia diafragmática congénita localizada habitualmente en la porción postero-externa izquierda (orificio de Bochdalek) por la que ascendería el riñón de una forma progresiva favorecida por una presión negativa, y el otro origen es el traumático, siendo también más frecuente en el lado izquierdo debido a la protección hepática contralateral. La incidencia de riñón intratorácico con hernia de Bochdalek, como sucede en nuestro caso, no llega al $0.25 \%$ (5). El lóbulo inferior del pulmón adyacente puede ser hipoplásico como consecuencia de la compresión renal (3).

Aunque los defectos congénitos del diafragma ocurren en el período neonatal, el $10-20 \%$ de los casos son diagnosticados tardíamente (6).

El riñón intratorácico secundario a una hernia diafragmática habitualmente es asintomático y no requiere tratamiento, aunque en ocasiones es responsable de un distress respiratorio severo en el período neonatal (4). Se han publicado casos excepcionales de carcinoma de células renales (7) o de litiasis sometida a nefrolitotomía percutánea sobre riñón ectópico intratorácico (8).

El diagnóstico suele llevarse a cabo al apreciar de forma incidental al realizar una radiografía de tórax, donde puede apreciarse una masa en el mediastino posterior que obliga al despistaje de una neoplasia pulmonar (9). EI TAC es una importante y eficiente herramienta para confirmar el diagnóstico, aunque también se podría utilizar la urografía intravenosa. 
En los casos en los que produzca sintomatología respiratoria el tratamiento consiste en la reparación quirúrgica del defecto diafragmático devolviendo el riñón a la cavidad abdominal.

\section{CONCLUSIONES}

La ectopia renal intratorácica es un hallazgo muy infrecuente, habitualmente asintomático, diagnosticado con frecuencia de manera incidental y que no suele requerir tratamiento.

\section{BIBLIOGRAFÍA Y LECTURAS RECOMENDADAS (*lectura de interés $y$ ** lectura fundamental)}

1. SOZUBIR, S.; DEMIR, H.; EKINGEN, G. y cols.: "Ectopic thoracic kidney in a child with congenital diaphragmatic hernia”. Eur. J. Pediatr. Surg., 15: 206, 2005.

*2. PASCUAL SAMANIEGO, M. y cols.: "Herniación intratorácica traumática del riñón izquierdo". Actas Urol. Esp., 27: 229, 2003.

**3. BELTRÁN ARMADA, J.R. y cols.: "Duplicidad pieloureteral y riñón intratorácico". Actas Urol. Esp., 28: 249, 2004.

*4. SFAXI, M. y cols.: "Intrathoracic kidney due to diaphragmatic hernia: A case report". Prog. Urol., 12: 477, 2002.

*5. KARAOGLANOGLU, N.; TURKYILMAZ, A.; EROGLU, A. y cols.: "Right-sided Bochdalek hernia with intrathoracic kidney". Pediatr. Surg. Int., 22: 1029, 2006.

6. KELES, S.; ARTAC, H.; ELMACI, M. y cols.: "Late presenting congenital diaphragmatic hernia associated with ectopic thoracic kidney”. Eur. J. Pediatr., 165: 571, 2006.

7. KUBRICHT, W.S.; HENDERSON, R.J.; BUNDRICK, W.S. y cols.: "Renal cell carcinoma in an intrathoracic kidney: Radiographic findings and surgical considerations". South Med. J., 92: 628, 1999.

8. LENZ, D.L.; CLAIR, D.L.; FETZER, A.E. y cols.: "Percutaneous nephrolithotomy of an intrathoracic kidney". Urology, 61: 462, 2003.

9. LOUZIR, B. y cols.: "Diagnosis of an opacity at the lung base: Intrathoracic kidney". Rev. Mal. Respir., 16: 207, 1999.
Casos Clínicos

Arch. Esp. Urol., 61, 5 (633-636), 2008

\section{CARCINOMA DE CÉLULAS ESCAMOSAS EN PELVIS RENAL BÍFIDA, TRAS NEFROLITOTOMÍA PERCUTÁNEA}

Sergio Martín Martín, Carlos A. Müller Arteaga, Elena García Lagarto, Juan Ramón Torrecilla García-Ripoll, José Ramón Cortiñas González y Ernesto Fernández del Busto.

Servicio de Urología. Hospital Clínico Universitario de Valladolid. Valladolid. España.

Resumen.- OBJETIVO: Describir un caso clínico de un paciente que presenta un carcinoma de células escamosas en una pelvis renal bífida, tras la realización de una nefrolitotomía percutánea.

MÉTODOS/RESULTADOS: Paciente varón de 68 años de edad, diagnósticado de carcinoma escamoso de pelvis renal, tras el estudio histológico de una nefrectomía polar inferior posterior a una nefrolitotomía percutánea por una litiasis coraliforme en hemirriñón izquierdo. El paciente sufrió una recidiva vesical un año y medio más tarde, se practicó una cistoprostratectomía radical, pero el fallecimiento se dio a los pocos meses ante la presencia de metástasis.
Sergio Martín Martín

Félix Martín, $10 \mathrm{~A}$ Íscar 47420 Valladolid. (España). risimartin7@hotmail.com

Trabajo recibido: 29 de septiembre 2007. 